\title{
Aspektualitas dalam Novel The Great Gatsby oleh F. Scott Fitzgerald
}

\author{
Eka Susylowati \\ English Department of Universitas Surakarta, Surakarta, Indonesia \\ Email: esusylowati@gmail.com
}

\begin{tabular}{|c|c|}
\hline Article Info & ABSTRACT \\
\hline Article history: & This research aims to reveal the form and marker of aspectuality in The \\
\hline Submitted March 22, 2019 & Great Gatsby novel written by F. Scott Fitzgerald. The data in this study are \\
\hline Revised April 2, 2019 & Great Gatsby. It was written by F. Scott Fitzaerald consists of three forms \\
\hline Accepted April 5, 2019 & of aspectuality namely perfective / completed, progressive, and repetitive / \\
\hline Published April 12, 2019 & $\begin{array}{l}\text { habitual. The aspect that is often used is perfective / completed aspiration. } \\
\text { Aspectuality markers used including perfective aspect characterized by }\end{array}$ \\
\hline Keywords: & $\begin{array}{l}\text { past verb or had }+ \text { past participle verb, while progressive aspect are } \\
\text { marked to be }+ \text { verb ing, and repetitive / habitual are marked with past } \\
\text { verb or infinitive forms. }\end{array}$ \\
\hline
\end{tabular}

Novel,

The Great Gatsby

\section{Corresponding Author:}

Eka Susylowati

English Department

Universitas Surakarta

Jl. Raya Palur Km. 5 Surakarta

Karanganyar, Indonesia 57772

Email: esusylowati@gmail.com

\section{PENDAHULUAN}

Bahasa merupakan hasil kreativitas manusia. Melalui bahasa, manusia dapat mengungkapakan ide, gagasan, pendapat penulis kepada pembaca, moderator kepada pendengar. Aspektualitas biasanya muncul pada kebanyakan bahasa, hanya saja cara mengungkapkannya yang berbeda-beda. Ada yang diungkapkan secara morfemis namun ada juga yang diungkapkan secara leksikal. Penggunaan bahasa dalam novel cukup berbeda dalam penggunaan wacana lain, seperti penggunaan bahasa dalam karya ilmiah, menyusun pidato, dan membuat undang-undang, membuat keputusan, dan lain sebagainya. Pada zaman globalisasi saat ini, karya sastra semakin relevan di lingkungan masyarakat. Bahasa Inggris merupakan bahasa internasional yang digunakan oleh masyarakat dan pelajar untuk berkomunikasi dari berbagai masyarakat di dunia. Mereka dapat belajar bahasa Inggris melalui berbagai media, antara lain: radio, televisi, majalah, buku, novel yang menggunakan bahasa Inggris. Novel merupakan karya sastra yang berisi gambaran maupun perilaku yang konkret tentang kehidupan masyarakat sehari-hari. Selain itu, kala dan aspektualitas yang bertalian di dalam bahasa Inggris.

Bahasa Inggris juga mengenal aspektualitas, seperti yang terdapat dalam bahasa Indonesia dan bahasa Jawa. Aspektualitas dalam bahasa Inggris dapat diungkapkan melalui bentuk verba dalam kalimat. Secara linguistik, aspektualitas dapat diklasifikasikan dalam tiga subkategori tata bahasa yang berkaitan dengan bentuk 
semantik verba. Adapun tiga bentuk semantik verba tersebut meliputi aspektualitas, temporalitas, serta modalitas. Tadjuddin (2005:3) mengatakan aspektualitas dan temporalitas mempelajari sifat-sifat keberlangsungan situasi (yaitu gejala luar bahasa yang berupa peristiwa, proses/aktivitas, keadaan) dilihat dari segi waktu yang menyertai keberlangsungan situasi tersebut sedangkan modalitas mempelajari situasi dari sudut pandang bermcam-macam sikap pembicara terhadap situasi yag berlangsung.

Dalam novel The Great Gatsby terdapat berbagai bentuk aspektualitas dalam bahasa Inggris. Novel The Great Gatsby menceritakan tentang Jay Gatsby yang dikenal sebagai bourjuis yang suka mengadakan pesta - pestanya yang glamor. Gatsby tampaknya masih terobsesi pada Daisy Buchanan yang pernah ditemuinya beberapa tahun silam. Dengan bantuan temannya, Nick Carraway, Gatsby akhirnya dapat bertemu kembali dengan Daisy Buchanan yang telah bersuami. Tidak memerlukan waktu lama bagi Nick untuk mengetahui sisi gelap Gatsby dari kehidupannya yang glamor. Dan obsesi Gatsby pada Daisy ternyata berujung pada tragedi. Contoh penggunaan aspektualitas digambarkan sebagai berikut:

I think we all believed for a moment that it had smashed in pieces on the floor. (Chapter IV, halaman 93).

Aspektualitas yang digunakan dalam kalimat ini yaitu perfective dengan ditulis past perfect. Bentuk penanda aspektualitas yang terdapat dalam novel The Great Gatsby sebagai berikut:

My Finn informed me that Gatsby had dismissed every servant in his house a week ago and replaced them with half a dozen others, who never went into West Egg Village to be beribed by the tradesmen, but ordered moderate supplies over the telephone. (Chapter VII, hal.119).

Penanda aspektualitas perfective ditandai past perfect yang ditunjukkan dengan pola had plus kata kerja lampau yaitu (dismissed). Selain cerita novel The Great Gatsby yang sangat menarik, dalam novel tersebut terdapat berbagai hal yang menarik untuk dianalisis, penulis sangat tertarik untuk meneliti aspektualitas dalam novel The Great Gatsby karena terdapat ciri khas tersendiri dalam novel tersebut. Berkaitan dengan hal tersebut, masalah pokok dalam penelitian ini sebagai berikut: 1). Bagaimana bentuk aspektualitas yang terdapat dalam novel The Great Gatsby? 2). Bagaimana penanda aspektualitas dalam novel The Great Gatsby?

\section{TEORI DAN METODOLOGI}

\section{Aspektualitas dan Bentuk-Bentuk Aspektualitas}

Secara linguistik, aspektualitas dapat diklasifikasikan dalam tiga subkategori tata bahasa yang berkaitan dengan bentuk semantik verba. Adapun tiga bentuk semantik verba tersebut meliputi aspektualitas, temporalitas, serta modalitas. Tadjuddin (2005:3) mengatakan aspektualitas dan temporalitas mempelajari sifat-sifat keberlangsungan situasi (yaitu gejala luar bahasa yang berupa peristiwa, proses/aktivitas, keadaan) dilihat dari segi waktu yang menyertai keberlangsungan situasi tersebut sedangkan modalitas mempelajari situasi dari sudut pandang bermcam-macam sikap pembicara terhadap situasi yag berlangsung. 


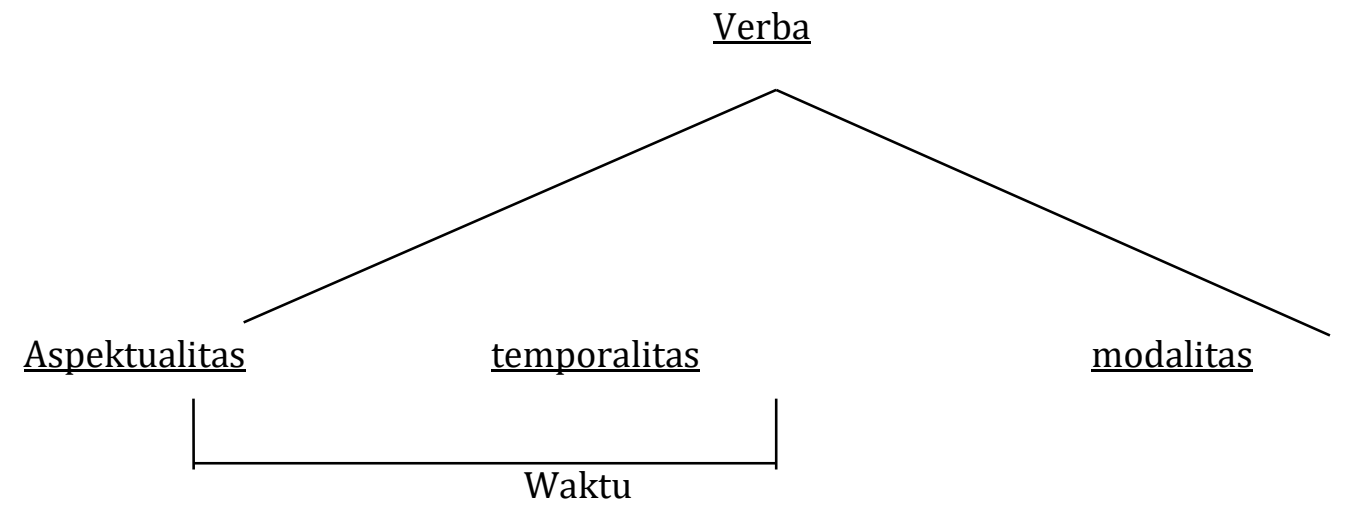

Aspektualitas bertalian dengan macam perbuatan tidak mempersoalkan tempatnya dalam waktu. Aspect is how such events are presented as ongoing or complete (Cann, 1993:233). Sementara itu, Verhaar (1996:239) mendefinisikan bahwa aspek menunjukkan segi arti verba yang berkaitan dimulainya, berlngsungnya, terjadinya, diulang tidaknya, selesai tidaknya, atau ada tidaknya hasil dari keadaan atau tindakan tersebut. Definisi aspektualitas menurut Comri (1976:3) bahwa aspects are different ways of viewing the internal temporal constituency of the situation. (Comri (1976:19) mengklasifikasikan aspek menjadi dua yaitu perfective dan imperfective. Situasi dapat berupa keadaan, peristiwa, dan proses. Keadaan sifatnya statis sedangkan peristiwa dan proses bersifat dinamis. Perfektif atau situasi lengkap dapat dilihat dari awal, tengah dan akhir. Imperfektif dengan konsep duratif menunjukkan proses sedang berlangsung termasuk habituatif.

Saeed (1997: 116) mengatakan bahwa aspektualitas penutur menghubungkan situasi dan waktu, namun dalam beberapa cara: sudah selesai, belum selesai, terjadi dalam waktu yang sangat singkat, terjadi selama periode waktu tertentu, atau terjadi beberapa kali dalam satu periode waktu tertentu. Charles Hockett (1958: 237) dalam bukunya Saeed (1997) mengatakan bahwa aspektualitas tidak berkaitan dengan satu titik dari suatu kejadian dalam suatu waktu, melainkan dengan distribusi temporalnya atau kontur. Di bawah ini dua kalimat yang dapat dijadikan contoh sebagai berikut:

(1) Ralph was building a fire-escape last week.

(2) Ralph built a fire-escape last week.

Kedua kalimat tersebut mendeskripsikan situasi pada waktu lampau tetapi dengan penekanan yang berbeda: kalimat (2) melihat fire-escape tersebut sudah selesai dibangun, sedangkan kalimat (1) tidak memberikan informasi apapun mengenai apakah fire-escape tersebut akan pernah selesai dibangun atau tidak. Perbedaan tersebut dapat muncul karena bentuk kata kerja masing - masing berada pada perpotongan dari kala dan aspektualitas dalam bahasa Inggris: was building adalah kala/aspektualitas past progressive pada kalimat (1) dan built kala/aspektualitas simple past pada kalimat (2). Hubungan antara aspektualitas dank ala ini dapat dilihat dengan memperhatikan bentuk utama dalam bahasa Inggris sebagai berikut:

English progressive form

(3) Present Progressive

Past Progressive

Future Progressive
I am listening

I was listening

I will be listening 
Progressives mendeskripsikan suatu kejadian yang sedang berlangsung dan berlanjut. Seperti yang sudah dijelaskan pada sebelumnya bahwa progressives digunakan dengan situasi dinamis dan tidak dijelaskan apakah proses tersebut berlangsung lama dan tidak diketahui apakah sudah selesai atau belum selesai. Pada past dan future, progressives dapat digunakan untuk menjelaskan suatu background kejadian dimana kejadian yang lain terjadi, misalnya:

(4) She was hiding the money when the doorbell rang.

(5) She'll be washing the car when you arrive.

Selain penggunaan seperti yang sudah dijelaskan, terdapat beberapa penggunaan lain dari progressive, yaitu untuk maksud maupun rencana dalam waktu dekat seperti pada kalimat (5).

(6) I'm catching the midnight train tonight.

\section{English perfect forms}

(7) Present perfect

Past perfect

Future perfect
I have listened

I had listened

I will have listened

Pada aspektualitas perfect, penutur menekankan pada hubungan antara kejadian kejadian pada waktu lampau dengan 'sekarang'. Pada kalimat yang paling sederhana yaitu pada present perfect, 'present' merupakan waktu pada saat berbicara. Hubungannya dapat bermacam-macam, yang pertama yaitu memberitahukan bahwa kejadian tersebut 'baru saja' terjadi. Hal tersebut dapat dilihat pada perbandingan dua kalimat berikut ini:

Don't run. The train has left.

?Don't run. The train left.

Yang kedua adalah seperti dalam kalimat berikut ini:

(10) The train has left.

Pada kalimat tersebut penutur menekankan pada konsekuensi sekarang dari kejadian tersebut, yaitu kereta api tersebut sudah tidak disini lagi. Hubungannya dengan 'sekarang' ini ditunjukkan dengan penggunaan kata keterangan already.

(11) I've already eaten.

Pada kenyataan, beberapa dialek dalam bahasa Inggris, kata keterangan tersebut dapat berfungsi sama dengan aspektualitas perfect, sehingga dapat menyebabkan redudansi. Oleh karena itu, kalimat diatas memiliki makna yang sama dengan kalimat berikut ini:

(12) I already ate.

Pada past dan future perfect, hubungannya terdapat pada lokasi sekunder dari waktu, yaitu suatu titik di waktu lampau atau akan datang dari waktu pada saat berbicara. Misalnya :

(13) The train had left.

Dalam kalimat tersebut titiknya merupakan waktu lampau yang berhubungan dengan kejadian berbicara dan bentuk kata kerjanya menghubungkan waktu sebelum titik tersebut dengan titik itu sendiri. Meskipun lokasi waktunya berbeda, interpretasinya sama dengan present perfect: segera, yaitu 'baru saja'; atau penekanan pada konsekuensi, pada saat itu kereta api tersebut sudah tidak ada di sana: 
He was too late. The train had left.

Pada future perfect, interpretasinya yaitu sama dengan titik di waktu yang akan datang:

(15) The train will have left.

Dengan demikian aspektualitas perfect yaitu relatif: penutur dapat menekankan pada hubungan dari satu titik dari suatu kejadian dalam masa lampaunya. Titik tersebut dapat berupa waktu dimana penutur berbicara, atau suatu waktu di waktu lampau atau waktu yang akan datang. Maka kalimat tersebut dapat dijelaskan sebagai 'suatu kejadian di masa lampau dari masa yang akan datang tetapi merupakan masa depan dari sekarang'.

English simple forms

(16) Simple present I listen

Simple past I listened

Simple future I will listen

Bentuk - bentuk tersebut merupakan bentuk kala simple yang dapat dianggap netral dalam hubungannya dengan aspektualitas: bergantung pada elemen lain dalam kalimat, dan juga bergantung pada kompleks, selain itu bentuk tersebut kompatibel dengan beberapa aspektualitas.

(17) I watched the six o'clock news.

Kalimat tersebut dapat diilustrasikan sebagai: satu kejadian di waktu lampau atau kebiasaan. Pada waktu sebuah kalimat simple past menggambarkan satu kejadian, sehingga kalimat tersebut menggambarkan kejadian tersebut sebagai kejadian yang telah selesai. Simple present memiliki lebih banyak batasan daripada past. Untuk sebagian kata kerja, penggunaan simple present untuk menunjukkan kejadian sekarang sudah banyak digantikan oleh penggunaan present progressive.

(18) a. What are you doing?

b. I'm looking for my ticket.

Dalam bahasa Inggris present progressive digunakan dimana dalam banyak bahasa lain digunakan simple present, contohnya dalam bahasa Perancis:

a. Qu'est-ce que tu fais?

b. Je cherche mon billet.

Namun demikian simple present dalam bahasa Inggris digunakan seperti present tense biasa dengan kata kerja stative, contohnya pada kalimat 20.
a. He knows the answer.

b. *He is knowing the answer.

Dengan kata kerja non-stative, simple present memiliki kegunaan lain yaitu untuk mendeskripsikan kebiasaan, seperti pada kalimat 21; untuk pernyataan umum atau universal, seperti pada kalimat 22, dan kadang untuk menggambarkan kejadian di waktu yang akan datang, seperti pada kalimat 23.

(21) She reads The Independent.

(22) Earthworms belong to the phylum Annelida.

(23) The ship departs tomorrow at dawn. 
Dari penjelasan tersebut merupakan penjelasan dari kala dan aspektualitas dasar dalam bahasa Inggris. Kesulitan mengetahui kala dan aspektualitas dapat muncul karena adanya batasan pada urutan kala dan aspektualitas dalam kalimat kompleks: contohnya, kalimat $a$ berikut benar sedangkan kalimat $b$ terdengar sangat aneh.

a. Joan walked out. She has left bag.

b. Joan walked out and has left her bag.

(25) a. You will get your result next Thursday. Come over for a drink.

b. ?When you will get your results next Thursday, come over for a drink.

Penutur dapat menggunakan kala dan aspektualitas yang tidak biasa dalam narasi untuk menekankan pada kekinian cerita. Contohnya dalam banyak bahasa, termasuk bahasa Inggris, penutur dan penulis menggunakan kala present untuk menceritakan perbuatan di masa lalu, hal ini biasa disebut historical present. Misalnya seperti pada kutipan novel John le Carre yang berjudul The Night Manager sebagai berikut:

(26). Jonathan is in the bedroom of the little flat in Luxor, with the moonlight sloping between the half-closed curtains. Sophie is lying on the bed in her white nightgown, eyes closed and face upward. Some of her drollnes has returned. She has drunk a little vodka. So has he. The bottle stands between them (1993:122).

Dalam novel tersebut kejadiannya merupakan suatu flashback, yang terjadi pada masa sebelum kejadian utama dari novel tersebut, seringnya digambarkan dalam kala past. Karena penggambarannya dengan kala present, semua kala/aspektualitas mengalami pergeseran, dimana present perfect dapat menggantikan past perfect dalam kalimat "She has drunk a little vodka.'

\subsection{Aspektualitas dan Temporalitas}

Berbeda dengan pengertian aspektualitas diatas, antara aspektualitas dan temporalitas terdapat perbedaan Pada temporalitas unsur waktu bersifat lokatif, mengacu pada waktu-waktu absolut (minggu lalu, kemarin, besok, dan lain sebagainya) dan/atau waktu relatif (dulu, sekarang, nanti, kelak) dan, pada umumnya, berorientasi pada waktu ujaran (speech moment). Pada temporalitas, dengan demikian, situasi dapat berlangsung sebelum waktu ujaran (kemarin, minggu lalu, dulu, dan lain sebagainya) atau bersamaan dengan waktu ujaran (hari ini, saat ini, sekarang, dan lain sebagainya) (Tadjudin, 1992:2627). Pada kategori aspektualitas waktu bukan merupakan lokasi tempat berlangsungnya situasi, sebaliknya, situasi itu sendiri yang menjadi lokasi tempat hadirnya waktu, oleh karena itu, waktu berada dalam situasi, bukan diluar situasi (Tadjudin, 1992: 27).

\subsection{Aspektualitas dan Modalitas}

Menurut Tadjuddin (2005:16) mengatakan bahwa aspektualitas berbeda dengan modalitas. Seperti halnya aspektualitas, kebanyakan bahasa yang memiliki kategori gramatikal aspek dan modus, perbedaan antara aspektualitas dan modalitas dapat diamati pada bentuk verba (Tadjuddin, 1992:28). Modalitas mendeskripsikan pandangan atau sikap subjektif pengujar. Sementara itu, aspektualitas mendeskripsikan pilihan yang objektif pengujar atas situasi yang diungkapkan oleh verba (predikat).

Penelitian mengenai aspektualitas dalam novel The Great Gatsby karangan F.Scott Fitzgerald merupakan penelitian kualitatif. Menurut Subroto (2007:6), disebut penelitian kualitatif karena data yang dikaji berupa kata-kata dan bukan angka atau data statistik. Sesuai dengan perspektif yang dipakai, penelitian kualitatif berusaha memahami makna dari fenomena-fenomena, peristiwa-peristiwa, dan kaitannya dengan orang-orang atau 
masyarakat yang diteliti dalam konteks kehidupan dalam situasi yang sebenarnya. Data dalam penelitian ini adalah data tulis yang berupa kata-kata, klausa, dan kalimat yang terdapat dalam novel The Great Gatsby. Populasi dalam penelitian ini meliputi seluruh kalimat atau ujaran yang terdapat di dalam novel The Great Gatsby. Data tersebut dikumpulkan sebanyak mungkin, yang dapat dianggap mewakili dari kala dan aspektualitas. Selanjutnya, contoh dalam penelitian tersebut ditentukan dengan menggunakan purposive sampling (teknik pengambilan sampel berdasarkan tujuan tertentu). Metode yang digunakan dalam pengumpulan data ini adalah metode simak (Sudaryanto, 2015: 206). Metode simak adalah metode yang dilakukan dengan cara menyimak penggunaan bahasa. Teknik lanjutan yang digunakan adalah teknik catat. Teknik catat yaitu mencatat data yang dikumpulkan dari penerapan hasil teknik sebelumnya (Sudaryanto, 2015:210). Teknik analisis datanya menggunakan metode distribusional.

\section{HASIL DAN PEMBAHASAN}

\subsection{Aspektualitas dalam Novel The Great Gatsby}

Bentuk aspektualitas yang terdapat dalam novel The Great Gatsby akan dijelaskan sebagai berikut:

\section{a. Perfective}

Aspektualitas perfective digunakan oleh Fitzgerald dalam mendeskripsikan sebagian besar kejadian yang dialami oleh tokoh-tokoh dalam karangan tersebut sebagai berikut.

\section{Data 1}

He came back from France when Tom and Daisy were still on their wedding trip, and made a miserable but irresistible journey to Louisville on the last of his army pay. He stayed there a week, walking the streets where their footsteps had clicked together through the November night and revisiting the out-of-the-way place to which they had driven in her white car. (Chapter VIII, halaman 158).

\section{Data 2}

I lived at West Egg, the - well, the less fashionable of the two, though this is a most superficial tag to express the bizarre and not a little sinister contrast between them. My house was at very tip of the egg, only fifty yards from The Sound, and squeezed between two huge places that rented for twelve or fifteen thousand a season. The one on my right was a colossal affair by any standard - it was a factual imitation of some Hotel de Ville in Normandy, with a tower on one side, spanking new under a thin beard of raw ivy, and a marble swimming pool, and more forty acres of lawn and garden. It was Gatsby's mansion. (Chapter I, halaman 11)

\section{Data 3}

The evening had made me light-headed and happy; I think I walked into a deep sleep as I entered my front door. So I don't know whether or not Gatsby went to Coney Island, or for how many hours he 'glanced into rooms' while his house blazed gaudily on. I called up Daisy from the office next morning, and invited her come to tea. (Chapter V, halaman 90). 
Pada data (1) mendeskripsikan bahwa hubungnnya dengan seseorang yang sudah selesai melakukan perbuatan. Data (2) menjelaskan apabila dilihat dari bentuk aspektualitasnya menunjukkan adanya suatu complete action. Data (3) menggambarkan bahwa perbuatan tersebut sudah selesai dilakukan. Aspektualitas perfective juga digunakan dalam kalimat langsung pada percakapan antar tokoh dalam novel tersebut.

\section{Data 4}

'You've dyed your hair since then, 'remarked Jordan, and I started, but the girls had moved casually on and her remark was addressed to the premature moon, produced like the supper, no doubt, out of caterer's basket. (Chapter III, halaman 39)

Aspektualitas perfective yang ditulis dalam past perfect diterjemahkan dalam bahasa Indonesia dengan menggunakan telah sehingga konsep bahwa kejadian tersebut telah selesai dapat dilihat dengan jelas.

\section{b. Progressive}

Aspektualitas progressive digunakan oleh Fitzgerald untuk menggambarkan kejadian kejadian yang sedang berlangsung dan juga dalam percakapan antar tokoh.

\section{Data 1}

There was dancing now on the canvas in the garden; old men pushing young girls backward in the eternal graceless circles, superior couples holding each other tortuously, fashionably, and keeping in the corners- and a great number of single girls dancing individualis-tically or relieving the orchestra for a moment of the burden of the banjo or the traps. (Chapter III, halaman 52)

\section{Data 2}

'Listen, 'said Tom, shaking him a little. 'I just got here a minute ago, from New York. I was bringing you that coupe we've been talking about. That yellow car I was driving this afternoon wasn't mine - do you hear? I haven't seen it all afternoon.' (Chapter VII, halaman 147).

Pada data (1) dan data (2) diatas menunjukkan kepada pembaca bahwa ada perbuatan atau kegiatan yang sedang terjadi.

\section{c. Repetitive/ Habitual}

Aspektualitas repetitive atau habitual digunakan oleh Fitzgerald untuk menjelaskan perbuatan atau kebiasaan yang terjadi berulang -ulang.

\section{Data 1}

About half-way between West Egg and New York the motor road hastily joins and runs beside it for quarter of a mile, so as to shrink away from a certain desolate area of land. This is a valley of ashes - a fantastic farm where ashes grow like wheat into ridges and hills and grotesque gardens; where ashes take the forms of houses and chimneys and rising smoke and finally, with a transcendent effort, of ash-grey men, who move dimly and already crumbling through the powdery air. (Chapter II, halaman 29)

\section{Data 2}

I usually find myself among strangers because I drift here and there trying to forget the sad thing that happened to me'He hasitated. (Chapter IV, hal.73) 
Data (1) menunjukkan bahwa adanya kebiasaan yang sering dilakukan. Hal ini ditandai dengan adanya joins, runs, dan grow. Data (2) Kalimat tersebut menunjukkan adanya peristiwa atau kebiasaan yang berulang-ulang seperti yang ditunjukkan pada contoh berikut ini I usually find myself among strangers. Hal ini ditandai dengan kata kerja infinitive yang menyatakan suatu kebiasaan.

\section{Data 3}

'I married him because I thought he was a gentleman,'she said finally. 'I thought he knew something about breeding, but he wasn't fit to lick my shoe.'

(Chapter II, hal.41)

Data (3) diatas menggambarkan bahwa kalimat tersebut termasuk dalam aspektualitas repetitive karena menunjukkan sesuatu yang dilakukan seseorang berulangulang. Hal ini dapat tampak pada kata thought.

\subsection{Penanda Aspektualitas Dalam Novel The Great Gatsby}

\section{a. Aspektualitas Perfective}

Biasanya aspek perfective ditandai dengan bentuk past tense, past perfect merupakan waktu pada saat berbicara. Hal ini akan diaplikasikan dalam contoh berikut ini:

\section{Data 1}

Miss Baker and I exchanged a short glance consciously devoid of meaning. I was about to speak where she sat up alertly and said "Sh!' in a warning voice. A subdued impassioned murmur was audible in the room beyond, and Miss Baker leaned forward unashamed, trying to hear. The murmur trembled on the verge of coherence, sank down, mounted excitedly, and then ceased altogether. (Chapter 1, halaman 21)

\section{Data 2}

I couldn't sleep all night; a fog-born was groaning incessantly on the Sound, and I tossed half-sick between grotesque reality and savage, frightening dreams. Toward dawn I heard a taxi go up Gatsby's drive and immediately I jumped out of bed and began to dress- I felt that I had something to tell him, something to warn him about, and morning would be too late. (Chapter 8, halaman 153)

Pada data (1) dan (2) diatas menunjukkan bahwa penanda aspektualitas perfective ditandai dengan bentuk past verb yang terdapat pada kata exchanged, sat, impassioned, leaned, trembled, ceased, tossed, heard, jumped, began, felt, had.

\section{Data 3}

They had spent a year in France for no particular reason, and then drifted here and there unrestfully wherever people played polo and were rich together. (Chapter 1, halaman 12).

\section{Data 4}

A man in a long duster had dismounted from the wrecck and now stood in the middle of the road, looking from the car to the tyre and from the tyre to the observers in a pleasant, puzzled way. (Chapter III, halaman 60)

\section{Data 5}


When Jordan Baker had finished telling all this we had left the Plaza for half an hour and were driving in a victoria through Central Park. (Chapter IV, halaman 84)

Data (3), (4), (5) tersebut mendeskripsipkan bahwa penanda aspektualitas perfective selain ditandai dengan past verb dapat juga ditandai dengan had + past participle verb, contohnya sebagai berikut: had spent, had dismounted, had finished.

\section{b. Aspektualitas Progressive}

Penanda aspektualitas progressive menggunakan bentuk continous tense yaitu to be $+\mathrm{V}$ ing. Hal ini akan dijelaskan sebagai berikut.

\section{Data 1}

'Has it?' When he realized what I was talking about, that there were twinkle-bells of sunshine in the room, he smiled like a weather man, like an ecstatic patron of recurrent light, and repeated the news to Daisy. (Chapter V, halaman 96)

\section{Data 2}

He was calling up at Daisy's request-would I come to lunch at her house tomorrow? Miss Baker would be there. Half an hour later Daisy herself telephoned and seemed relieved to find that I was coming. (Chapter VII, halaman 120)

Data (1) dan data (2) menunjukkan penanda aspektualitas progressive yaitu to be + $\mathrm{V}$-ing, hal ini dapat lihat seperti was talking, was calling, dan was coming.

\section{Data 3}

II know,'he said definitely, 'I'm one of these trusting fellas and I don't think any harm to nobody, but when I get to know a thing I know it. (Chapter VIII, halaman 165)

\section{Data 4}

'Where are we going?' she cried.

'How about the movies?'

(Chapter VII, halaman 131)

Data (3) dan data (4) menggambarkan bahwa penanda aspektualitas progressive yaitu to be + V-ing, hal ini ditunjukkan contoh berikut ini: I'm one of these trusting dan pada kalimat 'Where are we going?' she cried.

\section{c. Aspektualitas Repetitive/Habitual}

Penanda aspektulitas habitual biasanya digunakan bentuk past, present tense. Berikut ini contoh penanda aspektualitas habitual yang ditemukan dalam novel The Great Gatsby.

\section{Data 1}

Inside, the crimson room bloomed with light. Tom and Miss Baker sat at either end of long couch and she read aloud to him from the Saturday Evening Post - the words, murmurous and uninflected, running together in a soothing tune. The lamp-light, bright on his boots and 
dull on the autumn -leaf yellow of her hair, glinted along the paper as she turned a page with a flutter of slender muscles in her arms. (Chapter 1, halaman 24).

Pada data (1) diatas menunjukkan bahwa aspektualitas repetitive atau habitual dapat ditandai dengan past verb, hal ini tampak pada kata bloomed, sat, read dan turned.

\section{Data 2}

'Do you always watch for the longest day of the year and then miss it? I always watch for the longest day in the year amd then miss it.'

(Chapter 1, hal.18)

Data (2) tersebut mendeskripsikan bahwa aspektualitas repetitive/habitual yang menyatakan kebiasaan yang dilakukan ditandai dengan infinitive yaitu kata watch.

\section{SIMPULAN}

Pada bagian ini akan disajikan simpulan berdasarkan hasil penelitian dan pembahasan dalam novel The Great Gatsby karangan F. Scot Fitzgerald. Dalam novel tersebut terdapat tiga bentuk aspektualitas sebagai berikut perfective/completed, progressive, dan repetitive/habitual dimana aspektualitas yang sering digunakan adalah aspektualitas perfective/completed. Penanda aspektualitas yang digunakan antara lain: aspektualitas perfective ditandai dengan past verb atau had + past participle verb, sedangkan aspektualitas progressive ditandai dengan to be + verb ing, dan repetitive/habitual ditandai dengan bentuk past verb atau infinitive. Penelitian selanjutnya dapat diarahkan pada masalah tense dan aspek pada objek dan wilayah kajian yang berbeda.

\section{DAFTAR PUSTAKA}

Comrie, B. (1976). Aspect an introduction to the study of verbal aspect and related problems. Cambridge : Cambridge University Press.

Lyons, J. (1978). Semantics. Cambrigde : Blackwell Publisher Ltd.

Saeed, J.I. (1997). Semantics. Trinity College Bublin: Blackwell Publishers.

Scott, F. F. (1926). The great gatsby. Great Britain: Hunt Barnard Printing Ltd.

Subroto, E. (2007). Pengantar metode penelitian linguistik struktural. Surakarta: Sebelas Maret University Press.

Sudaryanto. (1993). Metode dan aneka teknik analisis bahasa. Yogyakarta: Duta Wacana University Press.

Sutopo, H.B. (2006). Metode penelitian kualitatif: dasar teori dan terapannya dalam penelitian. Surakarta: Sebelas Maret University Press.

Tadjuddin, M. (2005). Aspektualitas dalam kajian linguistik. Bandung: Alumni

Tadjuddin, M. (1992). Pengungkapan makna aspektualitas bahasa Rusia dalam bahasa Indonesia suatu telaah tentang aspek dan aksionalitas. Jakarta: Pusat Pembinaan Bahasa. 
Verhaar. J.W.M. (2012). Asas-asas linguistik umum. Yogyakarta: Gadjah Mada University Press. 